\title{
SELF-KNOWLEDGE OF GRADUATE STUDENTS IN NORTHERN BRAZIL
}

\author{
Rosângela Araújo Darwich ${ }^{1}$, Ana Letícia de Moraes Nunes² ${ }^{2}$ Lia Cristina da Silva Botega ${ }^{3}$, \\ \& Agnnes Caroline Alves de Souza ${ }^{3}$ \\ ${ }^{1}$ Graduate Program in Communication, Languages and Culture; Center for Health and Biological \\ Sciences, Universidade da Amazônia (Brazil) \\ ${ }^{2}$ Center for Health and Biological Sciences, Universidade da Amazônia (Brazil) \\ ${ }^{3}$ Graduate Program in Communication, Languages and Culture, Universidade da Amazônia (Brazil)
}

\begin{abstract}
The setting of goals and ways to achieve them is a possibility that the human species acquired with the development of language. Planning and executing, however, are different behaviors, as are the circumstances that favor or prevent them. Getting into graduate school in Brazil is still surrounded by uncertainties, including those regarding the future job market. In addition, the tasks required throughout the course present challenges for most students. Resilience, a necessary characteristic for overcoming adversity, can be investigated through different factors that favor decision-making and maintaining persistence towards the achievement of goals. In addition, self-knowledge mediates the development of these factors. Based on these fundamentals, we aimed to identify the impacts of storytelling videos, accompanied by reflection scripts, on the self-knowledge of students in graduate courses in Belém, in northern Brazil. For that, six videos, six reflection scripts and an on-line interview were prepared by the research group, in addition to an invitation to participate and a participant consent form. The videos were stored on the YouTube platform, and the other materials were made available through Google Forms. The social network WhatsApp was used to forward our invitation, the consent form and the links that allowed access to data collection instruments. Among students who underwent the initial procedures, ten went through all the steps and became participants in this research. The responses made it possible to relate the participants contact with the characters of the stories told in the videos to reflections on the need to pay more attention to themselves, in the sense of self-care and towards positive changes. It is also worth highlighting the recognition of the importance of social exchanges in effecting these changes. Although with different emphases, the results point to the occurrence of advances in the participants' self-knowledge, with practical consequences in $90 \%$ of cases. We conclude that, in the COVID-19 pandemic situation, internet-mediated research can achieve goals beyond data collection, generating positive effects on participants lives.
\end{abstract}

Keywords: Self-knowledge, graduate students, internet-mediated research, storytelling, YouTube.

\section{Introduction}

An action research entitled "Poetry in Daily Life: Experiential Groups and Resilience" is being accomplished at the Universidade da Amazônia (UNAMA), between 2020 and 2022. Due to the Covid-19 pandemic and the recommendations of public health agencies for social isolation in 2020, face-to-face group activities were suspended and the conduct of internet-mediated research was a promising alternative. The central objective remained: to generate knowledge and, at the same time, benefits to the participants. In this sense, this study focused on the self-knowledge of graduate students.

Many studies sought to investigate how to support resilience factors, in order to make it more likely to overcome challenges in crisis situations (Fischer \& Fröhlich-Gildhoff, 2019). In 2020, the radical changes in people's daily lives, given the high risk of illness and death, made clear the value of a resilient posture. Unusual but extremely necessary acts, such as the adoption of protective measures regarding the use of masks and constant hand hygiene, as well as maintaining physical distance are all the simpler to perform, the more you are resilient.

The realization of a graduate course can also be a challenge, even though just being admitted to it is alone the fulfillment of a dream. When we ask ourselves why the performance of different academic activities in parallel with the writing of a dissertation or thesis under the guidance of a teacher generates 
various concerns that, added to the uncertainties about the future job market, sometimes lead to mental disorders and / or psychosomatic diseases, the answer seems to value a relationship inversely proportional to the presence of resilience.

We realize the value of resilience while knowing that it cannot be trained directly. The alternative is to develop the so-called resilience factors, identified through different skills.

We assume that eleven personal characteristics correspond to factors or pillars of resilience: positive acceptance of change (recognition of changes and difficult situations as opportunities for growth), self-confidence (security, belief in yourself), self-efficacy (perception of one's abilities), good mood (optimism and lightness even in the face of problems), emotional control (maintaining balance and assertiveness), empathy (ability to perceive another person's emotional state), independence (ability to keep emotional and physical distance from other people, without falling into isolation), positive orientation towards the future (positive attitude towards life and towards goals), reflection (ability to maintain self-distancing in the face of a problem in order to reflect on the best solution), sociability (ability to create bonds, balancing the need for affection) and positive values (personal desire for well-being, extended to all humanity) (Cardoso \& Martins, 2013).

Self-knowledge is a trait that permeates the presence of these factors and gains prominence when we consider the importance of planning what we want to achieve and recognizing circumstances that favor or hamper the execution of what is planned. The individual who knows himself well, recognizes his strengths, his deficiencies and how to achieve the goals he creates. We perceived, therefore, the need for such a capacity for both decision making and persistence towards achieving goals (Brandenburg \& Weber, 2005; Baum, 1999; Skinner, 1976).

Improvement in self-knowledge can be achieved in different ways, but considering that it is a social product makes room for investigations that invest in spaces for reflection, as is the case in this study. "A person who has been 'made aware of himself' by the questions he has been asked is in a better position to predict and control his own behavior" (Skinner, 1974, p. 35). Therefore, we aimed to identify the impacts of storytelling videos, accompanied by reflection scripts, on the self-knowledge of students in graduate courses in Belém, in northern Brazil.

\section{Methods}

This internet-mediated research was carried out in the second half of 2020 by four psychologists who are part of a study and a research group at the Universidade da Amazônia. Two of the researchers are teachers, one is a master's degree student at the same institution and the other is a graduate of the program.

An invitation and research details were sent via cell phone application to master and doctoral students from two institutions, one private and the other public. The participants, ten graduate students, were selected from among twenty individuals who were invited for taking part in all the proposed activities.

The participants' identification is made by the letter " $F$ " or "M", meaning respectively "female" or "male", accompanied by their age. Thus, F57, is the oldest female participant and M24 is the youngest male participant.

The sample that makes up this study is non-probabilistic and participation was voluntary. It is considered heterogeneous, insofar as the selection of participants was based on an invitation to graduate students from two universities, without any other restrictions. In addition, the inclusion criterion was that participants completed all steps of the procedure.

Eight participants in this study are female (F25, F35, F45, F47, F49, F50, F52 and F57) and two, male (M24 and M49). Two of them were the same age (F49 and M49), two were in their 20s (M24 and F25), one was in their 30s (F35), four in their 40s (F45, F47, F49 and M49) and three in the 50s (F50, F52 and F57). Seven participants were studying for a master's degree. Of these, one was in the process of concluding the course, one started in 2018 (F25), two started it in 2019 (M24 and F35) and four, in 2020 (F45, F49, M49, F50 and F52). Of the three participants pursuing doctorates, one started the course in 2019 (F49) and two in 2020 (F47 and F57). Three participants were pursuing doctorates, one of which started the course in 2019 (F49) and two, in 2020 (F47 and F57).

Seven participants were taking a graduate course at a private university, in an interdisciplinary program in Communication, Languages and Culture (M24, F25, F45, F47, M49, F50 and F52). Another three were studying at a federal university, continuing in their home areas (F35, F49 and F57). The training of participants at undergraduate level varied between the courses of Psychology (F25, F35, F50 and F57), Pedagogy (F45 and F47), Letters (M24 and F52), Librarianship (M49), Dentistry (F49) and Law (F52). The latter two have two degrees: Dentistry and Psychology (F50) and Law and Letters (F52).

The instruments used, six children's storytelling videos, six reflection scripts with questions on the topics covered in each story and an online interview script, were developed by the research group. The videos were created from the narration of children's story books. A participant's consent form was also 
applied, as requested by the Research Ethics Committee of the Universidade da Amazônia, which approved the study via "Plataforma Brasil".

The WhatsApp social network was used to send participants the invitation to participate in the research, the consent form and the links that allowed access to the data collection instruments: scripts and videos with the narrations of the stories. The videos were made available in the "Reading with the Experiential Groups" playlist, on the YouTube platform, and Google forms were used to provide the scripts with questions for reflection. The videos correspond to the following children's stories: "Mamãe, você me ama?" ["Mommy, do you love me?"] (Joosse, 2007), "Quero colo!" [“I want lap!"] (Barbieri \& Vilela, 2016), Rosa Parks (Kaiser, 2017), "Entra aqui, sai lá" ["It goes in one ear and out the other"] (Winterberg, 2015), "Pedro vira porco-espinho" ["Pedro becomes porcupine"] (Tokitaka, 2017) and "Este é o lobo" ["This is the wolf"] (Rampazo, 2016).

Using the content analysis methodology (Bardin, 2001), three categories of analysis were created, corresponding to personal characteristics that participants believe they have, that they would like to improve or that they consider necessary for the current life context, as graduate students. They are present in one of the questions in the online interview, but they go through, directly or indirectly, all the steps of the intervention.

We put participants in a position to reflect on eleven personal characteristics that correspond to factors or pillars of resilience (Cardoso \& Martins, 2013) in order to favor the development of their self-knowledge. Thus, we chose videos with children's storytelling that made it possible to elaborate questions focused on these factors. Each of the six videos led to the creation of five questions and the investigation of six factors. Each factor was present three times throughout the total of videos, with the exception of emotional control, present in all of them. We believe that, in addition to balancing the presence of resilience factors, consistent and repeated reflections on one of them could help to promote self-knowledge, since different perspectives were raised around different axes, but also on a common axis.

In the closing online interview, three questions aimed to identify personal characteristics or resilience factors that the participants recognized in themselves after having reflected on them through exposure to the six story-telling videos and six reflection scripts. Participants should point out personal characteristics that they believe they have, that they would like to improve and that they consider necessary to meet the requirements of graduate studies. A fourth question aimed to investigate whether the participants perceived the occurrence of concrete personal changes based on the reflections experienced.

\section{Results and discussion}

In the online interview, the participants pointed out personal characteristics that they believe they have, that they would like to improve and that they consider necessary for them to cope with the requirements of the graduate program. Three resilience factors were grouped as they were always present together in the participants responses: self-confidence and self-efficacy, good mood and independence, and emotional control and reflection.

Six factors were identified by the participants in the three possibilities, in the sense of observing that they are present in their lives, which would be something to improve and necessary for the context of graduate studies: sociability, self-confidence / self-efficacy, positive orientation for the future and emotional control / reflection. In addition, empathy was identified only as a present factor, while positive values were identified as being present and also as a point to be improved, and positive acceptance of change, as present and necessary.

Factors that were both present and necessary were identified by F35 (sociability) and F57 (positive acceptance of change), which is very positive. On the other hand, self-confidence / self-efficacy was identified by four participants (F25, F45, F50 and F52) both as something that needs to be improved, as well as what is needed. In addition, the same participants also identified as something to be improved and necessary, respectively, the following factors: sociability (F25), F45 and F52 (self-confidence / self-efficacy) and emotional control / reflection (F50). This perspective is positive as it recognizes objectives to be achieved in the short term. Finally, F25 identified good humor / independence as something he already has, but still wants to improve.

All participants responded that the videos and scripts were an opportunity for reflection, allowing them to establish greater contact with themselves. Nine of them also described practical consequences of the act of reflecting throughout the interventions, all indicative of advancement in self-knowledge, such as the recognition of the need for commitment to better deal with stress (M24) and to acquire more sociability and better emotional control, in addition to movement to take more care of themselves (F25). Four other participants recognized the need to take more care of themselves (F35, F47, M49 and F50). In this regard, F35 replied: "I want to listen to myself more generously. We are in difficult times and we cannot handle everything". 
Three participants were less specific, indicating the possibility of changes broadly, without further details (F45, F49 and F57). Only one participant clearly identified the occurrence of change only as a possibility (F52): "the reflections helped me to remove emotions from inside me that were hidden, blocked. It is difficult to say whether there will be any changes".

The data can be complemented with information provided by the participants in the six reflection scripts that accompanied the videos, among which we highlight the answers to a question that is directly related to their self-perception regarding the relationship between commitment and performance they were having in the graduate studies and the value they attach to the grades they take in the evaluations they perform.

Only one participant, F35, proved to be self-demanding to the point of perceiving an unfavorable imbalance between commitment and performance: "I think the grades are fairly generous (haha), but I understand that in the subjects they are not only related to my writing. The evaluation also follows other elements". The other participants reported that they are satisfied with the result of the investment they are making in the studies.

Regarding the value they attach to the notes, F49 indicated that, "if I pass, it's ok". Three other participants clearly expressed themselves in this regard, all minimizing the importance of the notes. For M49, they "are only evaluation mechanisms" and for F45 "what matters is what you have done with dedication to your life while learning". From a perspective similar to that of F45, F57 expressed that "the other's expectation about us is his and does not correspond to what we really are [...], so we don't need to correspond and try to be what we are not to please the other".

The online interview was, theoretically, the moment when the thoughts elaborated during the experience with six videos and six reflection scripts could already demonstrate some kind of progress in the adopted perspectives. Therefore, we compared the reports of five participants (F35, F45, F49, M49 and F57) in two moments: when they completed the second reflection script and in the interview.

F45, F49 and F57 have in common the fact that they did not present details about the possibility of change precisely because they identified wide possibilities for personal changes after reflections. F45 initially minimized the value it gives to external evaluations, taking, for example, the grades in the subjects taken in graduate school ("what matters is what you did with dedication to your life while learning"). After, she identified self-confidence and self-efficacy as personal characteristics that would still need to improve and, even, that are necessary for the academic moment that she is experiencing. Therefore, it is possible that she has somehow realized that external evaluation has relevance to be considered as a parameter for personal decisions and reviews.

Initially, when referring to the value he assigns to the grades, F49 showed little self-demand and said that he is satisfied with the minimum necessary in relation to grades in the assessments. Subsequently, she was one of three participants to recognize that, based on the reflections she made, she could change widely, that is, in different areas of her life. This seems to imply the recognition that you can want more from yourself - and achieve more.

Initially, F57 was against the need to please the other, taking, for example, the external evaluation of the results of his studies. Then, she indicated that she had a necessary characteristic for the experience of graduate studies: positive acceptance of change (recognition of changes and difficult situations as opportunities for growth). We can see the fundamental role that external evaluations play when the participant evaluates them more generally in her life after having made other reflections about herself and her relationship with the world.

F35 is the participant who initially demonstrated to be very self-demanding. Later, she highlighted sociability (ability to create bonds, balancing the need for affection) as a characteristic of her that is necessary in graduate school and recognized the need to take more care of herself. We can argue that she may have realized that she has the necessary social skills to invest even in the way she treats herself, becoming more balanced in her self-assessments.

Initially, M49 considered the grades in the evaluations in a strictly rational way ("they are only evaluation mechanisms") and later, regarding internal and subjective evaluations, he recognized the need to take more care of himself.

\section{Conclusions}

Considering the objective of this study, the responses obtained through the different data collection instruments allowed us to verify that watching storytelling videos and having a space to write about themselves positively favored the participants self-knowledge. Taking time for themselves also seems to have contributed to the reaffirmation of the need for self-care, as well as the value of social exchanges for the realization of personal changes. 
Nine of the ten participants recognized the movement of change towards the construction of personal characteristics necessary for different experiences, including those they face in the graduate course. We can consider that, in the videos, the participants were faced with action models corresponding to the presence of resilience factors that convey an idea that there are always new possibilities for maturing with each challenge faced. The questions present in the reflection scripts also had this objective, adding new perspectives for evaluating the experiences presented.

Even with the Covid-19 pandemic situation, it was possible to continue studies that combine data collection with the opportunity for personal advances on the part of those participating in the research - in this case, mediated by the internet. It was not a simple move, as it was necessary to scanning four of the six children's storybooks and edit the six videos, with the voices of adults and children from different countries, in order to make them as attractive as possible. It is worth mentioning that the material, available on YouTube, remains used in different studies and interventions by our research group, with participants from all age groups and with children with atypical development.

We believe that this study, which uses videos and reflection guides, serves as a starting point for others, carried out with different objectives and with participants who share different characteristics. The proposed procedure can be adapted for face-to-face group meetings. In these cases, for example, the videos, one at each meeting, can be watched by the group of participants and the reflection guides can be used by the facilitators as a guide for intervention in the conversation.

\section{References}

Barbieri, S., \& Vilela, F. (2016). Quero colo! [I want lap!]. São Paulo: SM.

Bardin, L. (2001). L'Analyse de Contenu [Content Analysis]. Paris: Presses Universitaires de France.

Baum, W. M. (2005). Understanding behaviorism: Behavior, culture and evolution (2nd. ed.). Oxford: Blackwell Publishing.

Brandenburg, O. J. \& Weber, L. N. D. (2005). Autoconhecimento e liberdade no behaviorismo radical [Self-knowledge and freedom in radical behaviorism]. Psicologia-USF, 10 (1), 87-92

Cardoso, T., \& Martins, M. C. F. (2013). Escala dos Pilares da Resiliência [Scale of Pillars of Resilience]. São Paulo: Vetor.

Fischer, S., \& Fröhlich-Gildhoff, K. (2019). Chancen-gleich. Kulturelle Vielfalt als Ressource in frühkindlichen Bildungsprozessen. Manual zur Qualifizierung pädagogischer Fachkräfte [Equal opportunities. Cultural diversity as a resource in early childhood educational processes. Manual for the qualification of pedagogical specialists]. Stuttgart, Germany: Kohlhammer.

Joosse, B. (2007). Mamãe, você me ama? [Mommy, do you love me?]. Brinque Book.

Kaiser, L. (2017). Little People, Big Dreams: Rosa Parks. London: Frances Lincoln Children’s Books.

Rampazo, A. (2016). Este é o lobo [This is the wolf]. São Paulo: Farol Literário.

Skinner, B. F. (1976). About Behaviorism. New York: Vintage Books.

Tokitaka, J. (2017). Pedro vira porco-espinho [Pedro becomes porcupine]. São Paulo: Jujuba.

Winterberg, P. (2015). Entra aqui, sai lá! [It goes in one ear and out the other]. Kindle Edition. 